\title{
Tensile mechanical properties of fly ash concrete at early age for thermal stress analysis
}

\author{
Yoichi Mimura $^{1 *}$ D, Vanissorn Vimonsatit ${ }^{2}$, Itaru Horiguchi ${ }^{1}$ and Isamu Yoshitake ${ }^{3}$
}

\begin{abstract}
The present study investigates tensile properties of concrete with and without fly ash at early age, such as tensile Young's modulus, strength and creep. Some Young's modulus of fly ash concrete for thermal crack analysis was compared with the tensile Young's modulus, secant modulus, initial tangent modulus and linear modulus obtained from the direct tension test and compression test. The tensile creep test was also performed to obtain the specific creep behavior considering decrease in elastic strain due to stiffness development at early age during creep test. The results show that the Young's modulus for crack evaluation can be obtained from the compression test based on the stress range less than the splitting tensile strength, while the compressive secant modulus was smaller than the tensile Young's modulus. The decrease of the elastic strain at early age contributes more to the evaluation of the tensile creep than the use of the fly ash mixing.
\end{abstract}

Keywords: Early age, Tensile properties, Young's modulus, Splitting tensile strength, Specific creep, Elastic strain, Thermal stress, Fly ash

\section{Introduction}

Controlling cracks caused by various factors is an important issue for concrete engineers in order to construct durable structures. Volume change due to drying and hydration heat is a major factor in concrete cracking. Thermal cracks in wall type structures often penetrate cross-section so serious degradations such as corrosion of reinforcement are caused. Decreasing temperature rise contributes to the restraint of thermal stress at early age, and can be introduced by reducing the unit cement content and using admixtures. Juenger and Siddique [1] have reviewed recently published literature on concrete properties with supplementary cementitious materials including fly ash, ground granulated blast furnace slag, silica fume, calcined clays and natural pozzolans. This paper demonstrates that the field is far from mature in spite of the fact

\footnotetext{
* Correspondence: mimura@kure-nct.ac.jp

'Department of Civil and Environmental Engineering, National Institute of Technology, Kure College, Agaminami 2-2-11, Kure, Hiroshima 737-8506, Japan

Full list of author information is available at the end of the article
}

that supplementary cementitious materials have been used and researched for decades.

One of the most ordinary concrete admixtures as a byproduct of other industries is fly ash from coal-fired power plants. Fly ash is generally used as partial replacement of cement in concrete, so hydration heat can be reduced [2]. Clarifying the tensile stress reduction effect of fly ash on crack control can lead to expansion of its use, and active utilization of fly ash can improve the performance of concrete, reduce environmental impact, and contribute to the establishment of a recycling-oriented society.

Numerical simulations are often performed in order to predict thermal cracking. Tensile properties, such as Young's modulus, strength and creep, are required for an estimation of tensile stress which causes thermal cracking. Tensile Young's modulus is directly dependent on the prediction of tensile stress and is one of the important input data for Finite element method (FEM) analysis. Shen et al. [3] conducted uniaxial tension test 
using prismatic specimen for uniaxial tensile strength and tensile Young's modulus at early age. Yoshitake et al. [4] also investigated tensile properties of high volume fly-ash (HVFA) concrete. Young's modulus in Japan is generally a secant modulus obtained from a compression test. Mimura et al. [5] reported that the tensile Young's modulus based on the direct tension test by using the slender reinforced concrete (RC) specimen is higher than the compressive modulus (secant modulus) at early age. Swaddiwudhipong et al. [6] also investigated tensile behavior of concrete at early age by using the direct tension test. Their test program included ground granulated blast furnace slag and pulverized fuel ash in concrete.

Tensile creep, which is inelastic strain, mitigates the tensile stress caused by restraint of concrete shrinkage including drying and temperature change, so numerical simulation without the relaxation due to creep might induce the overestimation of tensile stress. Shen et al. [7-9] reported tensile creep behavior at early age. Creep behavior of concrete loaded at early age is greater than that of mature concrete, so tensile stress mitigated by creep at early age is required for accurate FEM simulation of thermal cracks.

In this study, several Young's moduli obtained from compression test, which can be performed with general equipment, were compared with the tensile Young's modulus obtained from the direct tension test by using the unique apparatus and specimen. Compressive Young's moduli in the present study were secant modulus and initial tangent modulus. In addition, linear modulus which is taken from a regression line of a compressive stress-strain curve in the range of stresses less than the splitting tensile strength was also evaluated. These Young's moduli of fly ash concrete were determined by the compression tests or the direct tension tests.

The tensile creep tests using the dog-bone shaped specimen of concrete with and without fly ash were conducted at the age of 3 or 7 days, and the loading was sustained for 14 days. The loading stress was constant during the tensile creep test and was set at $30 \%$ or $40 \%$ of the splitting tensile strength. It should be noted that elastic strain at an early age decreases with the age of concrete. However, the effect of the decrease in elastic strain during creep test has hardly been mentioned in most investigations $[10,11]$. This study takes a consideration of stiffness development during creep test to distinguish actual creep and elastic strains based on superposition principle. In order to obtain the tensile mechanical properties development during creep test, splitting tensile strength and Young's modulus were examined at various ages. The elastic strains during the tensile creep test were also measured by temporary unloading.
Table 1 Materials

\begin{tabular}{lll}
\hline Property & Materials & Density \\
\hline Water & Tap water & $1.00 \mathrm{~g} / \mathrm{cm}^{3}$ \\
Cement & Ordinary Portland cement & $3.16 \mathrm{~g} / \mathrm{cm}^{3}$ \\
Fly ash & Class II & $2.24 \mathrm{~g} / \mathrm{cm}^{3}$ \\
Fine aggregate & Crashed sand & $2.62 \mathrm{~g} / \mathrm{cm}^{3}$ \\
Coarse aggregate 1 & Crashed stone $20-15 \mathrm{~mm}$ & $2.67 \mathrm{~g} / \mathrm{cm}^{3}$ \\
Coarse aggregate 2 & Crashed stone $15-5 \mathrm{~mm}$ & $2.67 \mathrm{~g} / \mathrm{cm}^{3}$ \\
Admixture 1 & Air entraining water reducing agent & $1.07 \mathrm{~g} / \mathrm{cm}^{3}$ \\
Admixture 2 & Air entraining agent for fly ash & $1.04 \mathrm{~g} / \mathrm{cm}^{3}$ \\
\hline
\end{tabular}

$a^{a}$ : diluted solution (diluted 100 times with water)

\section{Methodology}

Materials and mixture proportions

The concrete materials in this study are given in Table 1. The cementitious materials used in the present study were ordinary Portland cement and fly ash. The fly ash was class II defined in Japanese Industrial Standard (JIS) A 6201 [12]. Unit content of $\mathrm{SiO}_{2}$ and loss of ignition in the fly ash was $59.8 \%$ and $2.1 \%$, respectively. The fly ash had a Blaine fineness of $375 \mathrm{~m}^{2} / \mathrm{kg}$. The fine aggregate was crashed sand with a fineness modulus of 2.71 . The coarse aggregates were crushed stone with the maximum size of $15 \mathrm{~mm}$ and $20 \mathrm{~mm}$. The principal components of the air entraining water reducing agent used in this study are a lignin sulfonate and an oxycarboxylic acid. The unburned carbon contained in fly ash decrease the effect of the air entraining water reducing agent, so the air entraining agent for fly ash was mixed for restraining the influence of the unburned carbon. These admixtures are commercially available in Japan.

The mixture proportions in this study are given in Table 2. The normal concrete with the water cement ratio of 0.55 is generally used for infrastructures in Japan. Hence the water-cementitious material ratio $(w / \mathrm{cm})$ for all tested concrete was designed as 0.55 . The amount of fly ash used in the present study was $20 \%$ by mass of the

Table 2 Mixture proportions of concrete

\begin{tabular}{lll}
\hline & Normal concrete & Fly ash concrete \\
\hline Mix I.D. & $\mathrm{N}$ & FA \\
W/cm & \\
Water & 0.55 & 0.55 \\
Cement & $165 \mathrm{~kg} / \mathrm{m}^{3}$ & $165 \mathrm{~kg} / \mathrm{m}^{3}$ \\
Fly ash & $300 \mathrm{~kg} / \mathrm{m}^{3}$ & $240 \mathrm{~kg} / \mathrm{m}^{3}$ \\
Fine aggregate & $0 \mathrm{~kg} / \mathrm{m}^{3}$ & $60 \mathrm{~kg} / \mathrm{m}^{3}$ \\
Coarse aggregate 1 & $844 \mathrm{~kg} / \mathrm{m}^{3}$ & $833 \mathrm{~kg} / \mathrm{m}^{3}$ \\
Coarse aggregate 2 & $499 \mathrm{~kg} / \mathrm{m}^{3}$ & $493 \mathrm{~kg} / \mathrm{m}^{3}$ \\
Admixture 1 & $499 \mathrm{~kg} / \mathrm{m}^{3}$ & $493 \mathrm{~kg} / \mathrm{m}^{3}$ \\
Admixture 2 & $3.00 \mathrm{~kg} / \mathrm{m}^{3}$ & $2.40 \mathrm{~kg} / \mathrm{m}^{3}$ \\
\hline :Watecmen & $0 \mathrm{~kg} / \mathrm{m}^{3}$ & $16.8 \mathrm{~kg} / \mathrm{m}^{3}$
\end{tabular}

$a^{a}$ Water-cementitious material ratio $(\mathrm{cm}=$ cement + fly ash) 


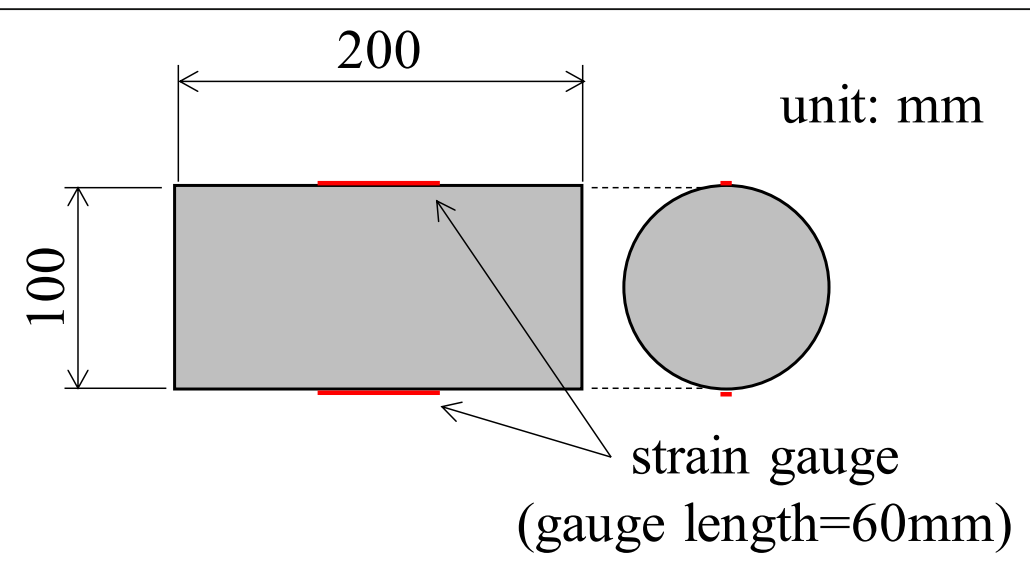

Fig. 1 Cylindrical specimen for the splitting tensile strength test and the compression test

cement of the normal concrete. The targeted slump and the targeted air amount were $8 \pm 2.5 \mathrm{~cm}$ and $4.5 \pm 1.5 \%$.

In this study, fine aggregate, cement and fly ash were firstly mixed for $30 \mathrm{~s}$ by using a biaxial forced mixer. Then the water blended the air entraining water reducing agent and the air entraining agent for fly ash was added and mixing was performed for 1 min. Finally, concrete was mixed for $2 \mathrm{~min}$ after both coarse aggregates were added to the mixer. Just after mixing, slump and air amount were measured. Measured slump and air amount of all concrete in this study were in the range of the target.

\section{Test specimens}

A cylindrical specimen with a diameter of $100 \mathrm{~mm}$ and a height of $200 \mathrm{~mm}$ as shown in Fig. 1 was used for splitting tensile test (JIS A 1113) [13] and compression test. Strain gauge with gauge length of $60 \mathrm{~mm}$ was attached at the center of both side faces of each specimen for compression test. The dog-bone shaped specimen for the direct tension test and the tensile creep test is shown in Fig. 2. A small mold strain gauge, having a thermometric function and gauge length of $50 \mathrm{~mm}$, was embedded in the center of the cross-section of the specimen. After casting concrete, all specimens were carried into the curing room to be cured at a room temperature of $20 \pm 1{ }^{\circ} \mathrm{C}$ for $24 \mathrm{~h}$ before demolding. After that, the specimens were cured underwater in a tank installed in the curing room until load tests. Water temperature in the tank was $16 \pm 1^{\circ} \mathrm{C}$.

\section{Test program for Young's modulus}

In this study, Young's moduli evaluated by several procedures, based on data obtained from the direct tension test and the compression test, were compared. The direct tension test by using a dog-bone shaped specimen and a loading apparatus shown in Fig. 3 was carried out in order to obtain the tensile Young's modulus. The load was manually applied to the tip of the steel arm. The specimen was loaded until its failure. The load and strain were recorded at every step of strain increment of $10 \times 10^{-6}$. After each recording, the load was temporarily removed and the strain at unloading was measured. Such loading / unloading cycle was performed twice at each strain level. The reason for this loading procedure is to eliminate the influence of inelastic strain as much

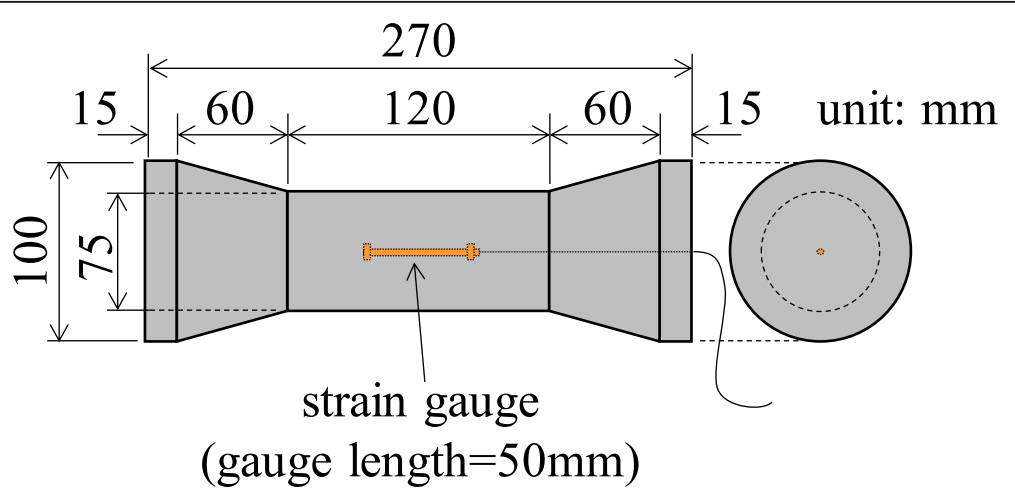

Fig. 2 Dog-bone shaped specimen for the direct tension test and the tensile creep test 


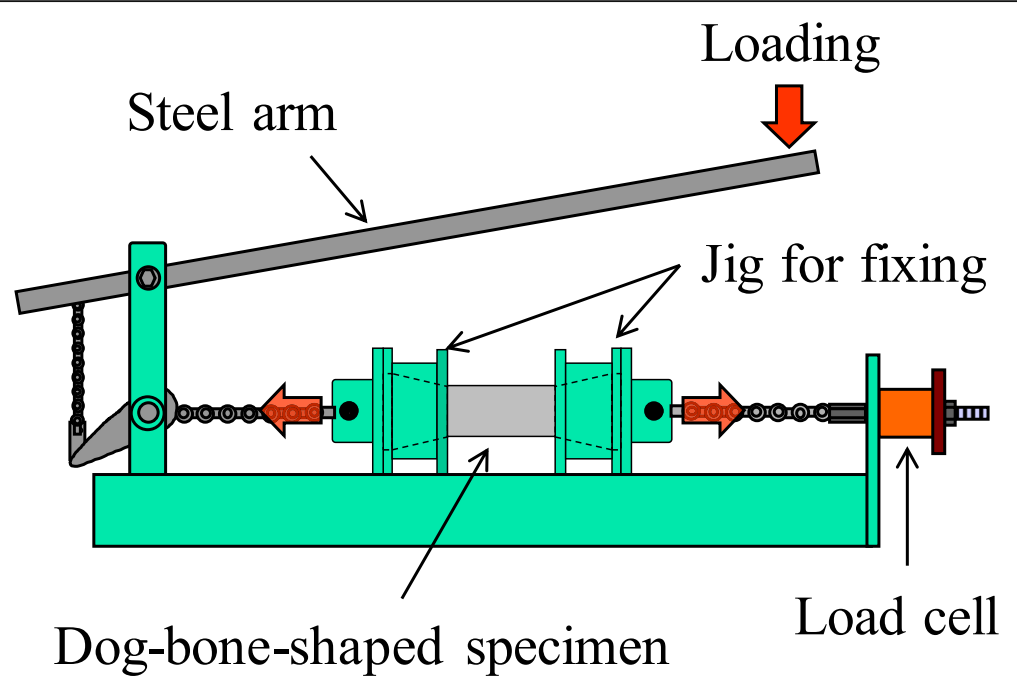

Fig. 3 Test setup of the direct tension test

as possible for the Young's modulus. The residual strain measured at unloading is inelastic strain due to microcracks and so on, and should not be included in strain used for evaluating Young's modulus.

Compression test based on JIS A 1149 [14] with the cylindrical specimen and universal testing machine was also conducted for obtaining a compression Young's modulus. The loading rate in this compression test was automatically controlled at $0.2 \mathrm{MPa} / \mathrm{sec}(1.6 \mathrm{kN} / \mathrm{sec})$ by a universal testing machine. The load and strain were recorded at every load increment of $10 \mathrm{kN}$. The specimen was loaded until its failure. The general compressive Young's modulus (hereinafter referred to as secant modulus) was evaluated from the data at the strain of $50 \times 10^{-6}$ and the data at the load of $1 / 3$ of the maximum load. In addition to compression test based on JIS, the compression test with the same procedure of the direct tension test, repeating loading and unloading, was also conducted. In this compression test, the loading ended after the stress corresponding to the splitting tensile strength was recorded. Thereafter, the same specimen for this compression test was used to perform a compression test based on JIS described above. In this investigation, the direct tension test and compression test by using specimens with fly ash concrete at the age of 7 days; 4 specimens were used for each test.

\section{Test program for tensile creep}

The test setup of the tensile creep test in the present study is shown in Fig. 4. A weight was placed on the tip of the steel arm for loading. The loading apparatus was installed in the water tank in the curing room (room temperature $=20 \pm 1^{\circ} \mathrm{C}$ ). The water temperature was kept at $16 \pm 1{ }^{\circ} \mathrm{C}$. In this study, the tensile creep test was conducted in water in order to eliminate the influence of drying, so "creep" in the present study means a basic creep of saturated concrete. The non-loaded specimen was placed in the same tank. The strain of the nonloaded specimen was subtracted from that of the loaded specimen, so strains caused by factors other than loading were removed as much as possible. Measurement was carried out at one-hour intervals by using a data logger. The measurement items were strain and temperature of the dog-bone shaped specimen and water temperature.

Table 3 gives the details of the tensile creep test. The loading started at the age of 3 days or 7 days, as it was found in FEM analysis of a wall structure that thermal stress turned from compression to tension in a week [15]. Thermal cracks occur at the age of around 2 weeks, so the loading was sustained for 14 days. According to Davis-Granville's law, stress less than $1 / 3$ of strength is proportional to creep strain, so the loading stress in this study was set to $30 \%$ or $40 \%$ of the splitting tensile

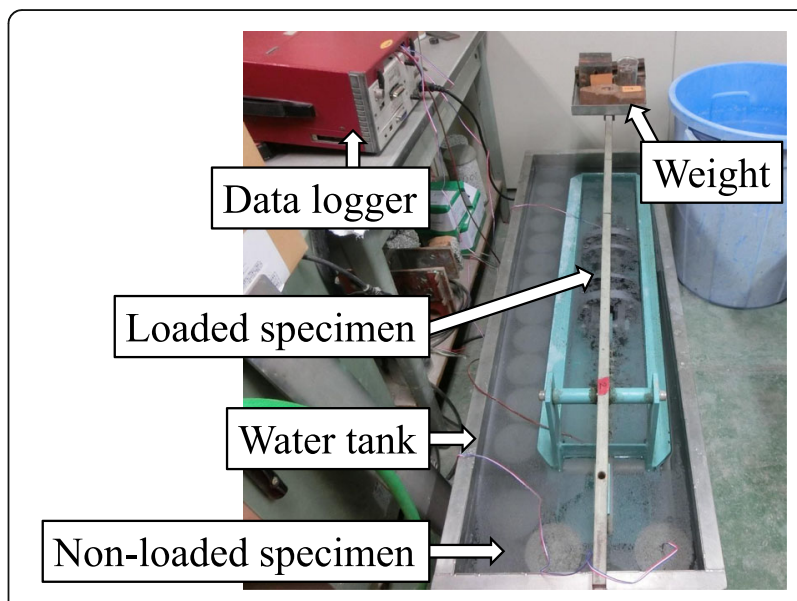

Fig. 4 Test setup of the tensile creep test 
Table 3 Details of the tensile creep test

\begin{tabular}{llllll}
\hline Test I.D. & Mix I.D. & Loading age & s/s ratio ${ }^{\boldsymbol{a}}$ & $\begin{array}{l}\text { Measurement of Young's modulus } \\
\text { and splitting tensile strength }\end{array}$ & $\begin{array}{l}\text { Measurement of elastic } \\
\text { strain }\end{array}$ \\
\hline N3-30a & $N$ & 3 days & $30 \%$ & $3,7,10,14$ and 17 days & At starting and ending \\
N3-30b & $N$ & 3 days & $30 \%$ & $3,5,7,10,14$ and 17 days & Every day \\
N3-30c & $N$ & 3 days & $30 \%$ & $3,5,7,10,14$ and 17 days & Every day \\
N3-40a & $N$ & 3 days & $40 \%$ & $3,5,7,9$ and 17 days & Every day \\
N3-40b & $N$ & 3 days & $40 \%$ & $3,5,7,9$ and 17 days & Every day \\
N3-40c & N & 3 days & $40 \%$ & $3,5,7,9$ and 17 days & Every day \\
N7-30 & N & 7 days & $30 \%$ & $7,9,11,14,17$ and 21 days & At starting and ending \\
FA3-30a & FA & 3 days & $30 \%$ & $3,7,10,14$ and 17 days & At starting and ending \\
FA3-30b & FA & 3 days & $30 \%$ & $3,5,7,10$ and 17 days & Every day \\
FA3-30c & FA & 3 days & $30 \%$ & $3,5,7,10$ and 17 days & Every day \\
FA3-40a & FA & 3 days & $40 \%$ & $3,5,7,9$ and 17 days & Every day \\
FA3-40b & FA & 3 days & $40 \%$ & $3,5,7,9$ and 17 days & Every day \\
FA3-40c & FA & 3 days & $40 \%$ & $3,5,7,9$ and 17 days & Every day \\
FA7-30 & FA & 7 days & $30 \%$ & $7,9,11,14,17$ and 21 days & At starting and ending \\
\hline
\end{tabular}

${ }^{a}$ : Stress/strength ratio

strength at the loading-start age. The strain at temporary unloading was recorded in order to measure the elastic strain during the creep test, and the Young's modulus and the splitting tensile strength were examined at the ages given in Table 3.

\section{Test results and discussion}

\section{Comparison of Young's moduli}

Figure 5 shows an example of the stress-strain responses in the direct tension test. In the direct tension test for the tensile Young's modulus, the load was temporarily removed for measurement of strain at unloading. The

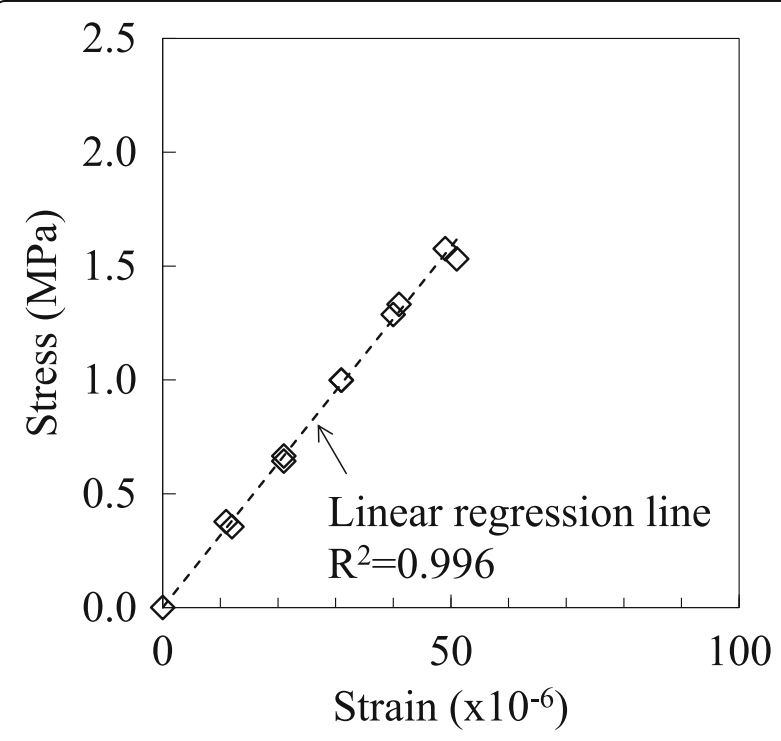

Fig. 5 Stress - strain responses in the direct tension test residual strain at unloading is inelastic, so the strain including the residual strain is inappropriate for the evaluation of Young's modulus. The strain shown in Fig. 5 was evaluated by subtracting from strain at loading to residual strain at unloading. The stress-strain responses were almost linear up to the maximum point, as shown in Fig. 5, so the gradient of the regression line was taken as the tensile Young's modulus.

Figure 6 presents the result of the compression test with the same procedure of the direct tension test. The $f_{t}$ in Fig. 6 means the splitting tensile strength at the test

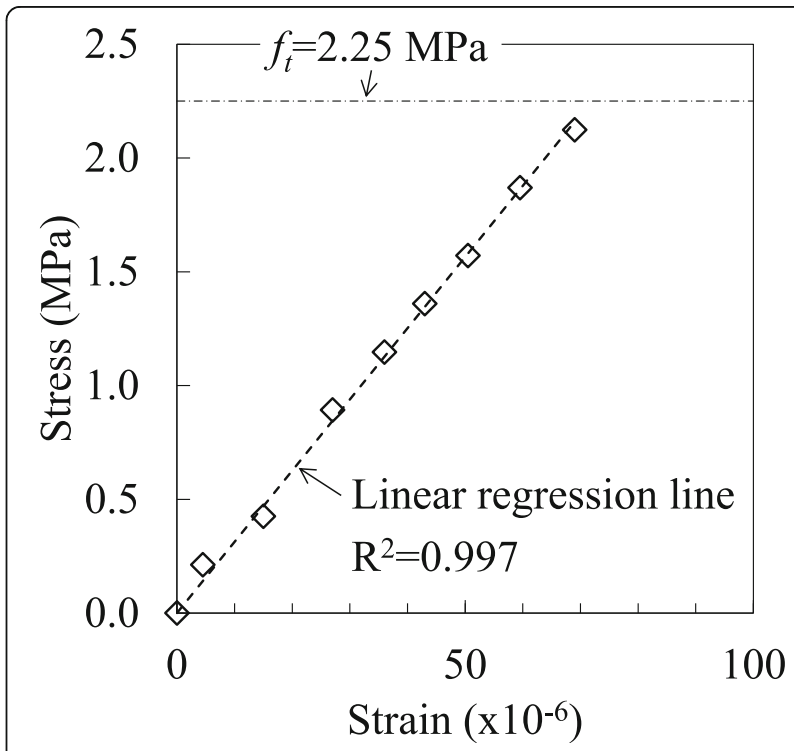

Fig. 6 Stress - strain responses in the compression test with the same procedure of the direct tension test 
age (7 days). One of the compressive Young's modulus in this study (hereinafter referred to as linear modulus) was obtained from the slope of this linear regression line.

The result of the compression test based on JIS is demonstrated in Fig. 7. The result in Fig. 7 was regressed by the cubic equation shown in Eq. (1).

$$
\sigma=\mathrm{a} \cdot \varepsilon^{3}+\mathrm{b} \cdot \varepsilon^{2}+\mathrm{c} \cdot \varepsilon
$$

where, $\sigma$ is stress $(\mathrm{MPa}), \varepsilon$ is strain $\left(\times 10^{-6}\right), a, b$ and $c$ are coefficients.

The experimental data was accurately regressed by the cubic curve in Eq. (1), and $R^{2}$ (coefficient of determination) was more than 0.99 . The coefficient $c$ in Eq. (1) corresponds to the initial tangent modulus. The secant modulus, applied as a general Young's modulus of concrete in Japan was evaluated from the data at the strain of $50 \times 10^{-6}$ and the data at the stress of $1 / 3$ of the compressive strength $\left(f_{c}\right)$, as shown in Fig. 7.

Figure 8 shows the results of the tensile Young's modulus and the compressive Young's moduli (the secant modulus, the initial tangent modulus and the linear modulus). The secant modulus was obviously smaller than the tensile Young's modulus, with the average value being $87 \%$ of the tensile Young's modulus. This result indicates that tensile stresses evaluated using the secant modulus from the compression test might be underestimated. On the other hands, the initial tangent modulus and the linear modulus were nearly equal to the tensile Young's modulus. This was because the stress - strain relationship shown in Fig. 6 was almost linear in the stress range less than the tensile strength and the stiffness was equivalent regardless of tensile stress and compressive stress. However, the stress was not proportional to the strain as the stress increased, particularly beyond
$1 / 3$ of the compressive strength, as shown in Fig. 7 . Therefore, the difference between the tensile Young's modulus and the secant modulus can be caused by the difference in the level of the stress and strain used for the evaluation of the Young's modulus. In other words, the Young's modulus evaluated from the compressive stress-strain curve at the stress range less than the splitting tensile strength may be suitable for crack estimation even if the stress field differs.

In addition, the loading apparatus and dog-bone shaped specimen used in the direct tension test shown in Figs. 2 and 3 are not typical, so it is difficult to obtain the development evaluation of Young's modulus at early ages based on many tests. The compression tests by using a typical cylindrical specimen can be relatively easily performed at the various ages of concrete. The cylindrical specimen for the initial tangent modulus has already fractured after the compression test. The compression test for the initial tangent modulus requires many specimens in order to obtain stiffness development as ages. The loading stresses in the compression test for the linear modulus are below the tensile strength. The cylindrical specimen for the linear modulus hardly has a failure and can be repeatedly used for the compression tests at the various ages, so stiffness development evaluated by the linear modulus includes less errors between specimens.

\section{Results of the splitting tensile strength and the Young's modulus}

The Young's modulus (the linear modulus) obtained from the compression test and the splitting tensile strength during the tensile creep test are shown in Figs. 9 and 10, respectively. The development of the Young's modulus and the splitting tensile strength of the fly ash

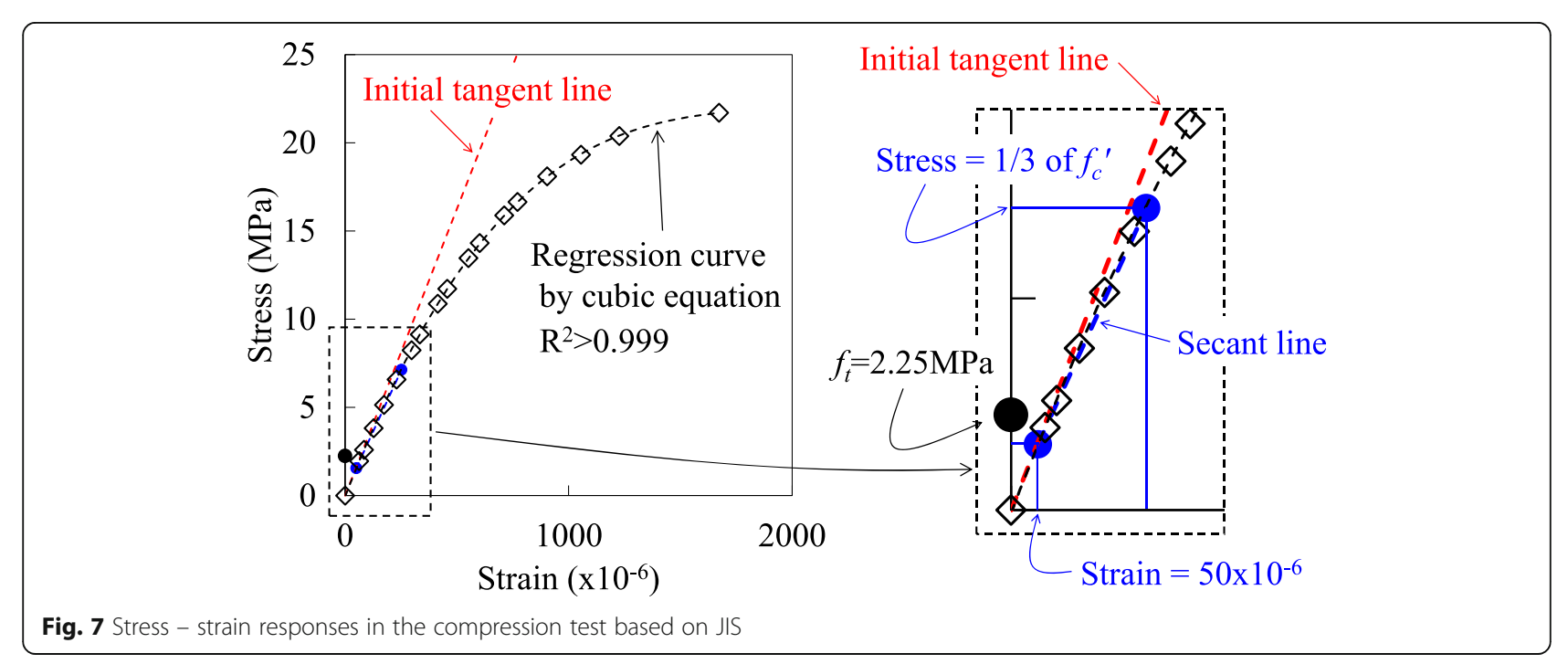




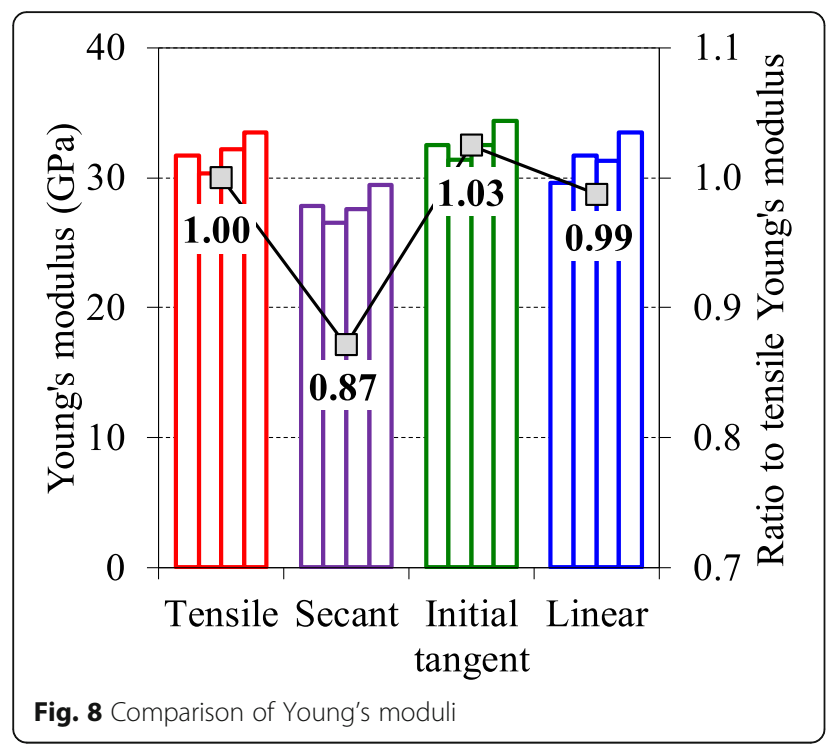

concrete is more gradual than that of the normal concrete. The stiffness of the normal concrete and the fly ash concrete have been developing, so the elastic strain could be decreasing during the tensile creep test with a constant load.

The loading stress determined based on the splitting tensile strength at the loading age is given in Table 4 . The stress/strain ratio was set to $30 \%$ or $40 \%$ at the loading start and was gradually decreased during the tensile creep test due to development of tensile strength as shown in Fig. 10.

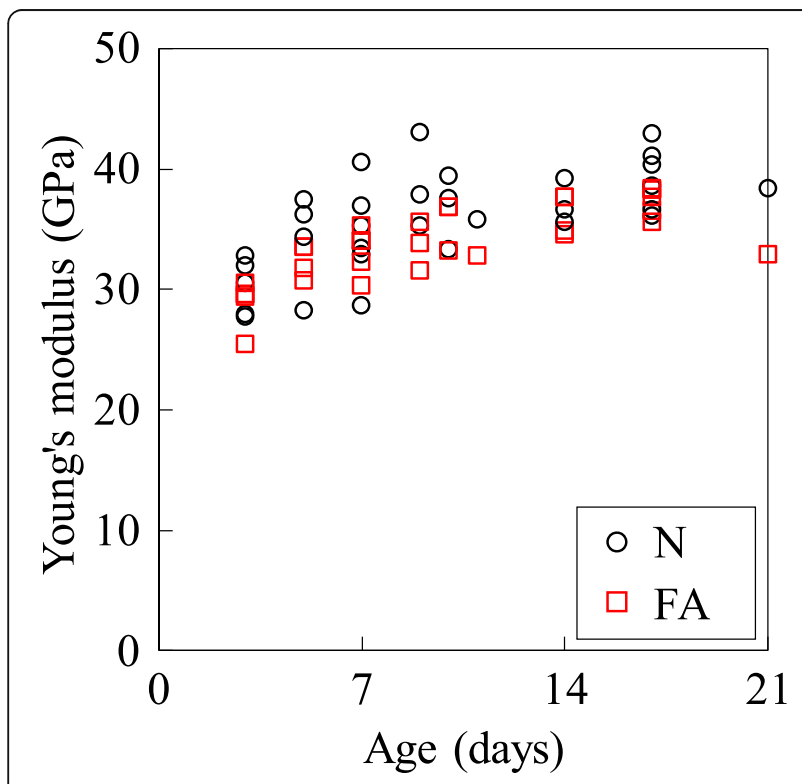

Fig. 9 Young's modulus during the tensile creep test

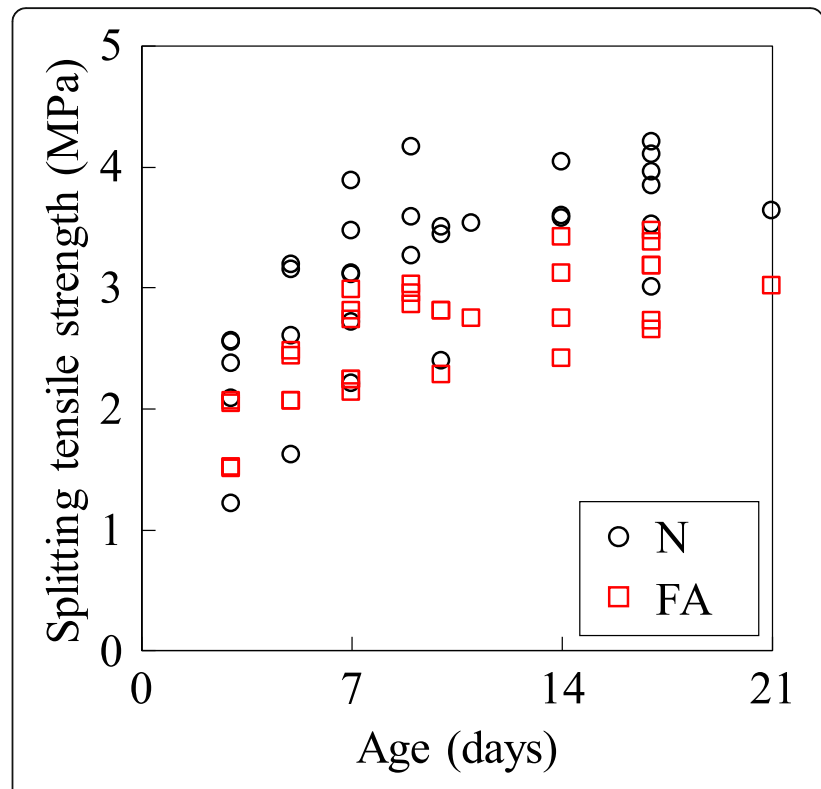

Fig. 10 Splitting tensile strength during the tensile creep test

\section{Creep behavior}

Figure 11 shows an example of the strain behavior of the loaded specimens and the non-loaded specimens. The data between the loading strain and non-loading strains are the strains at temporary unloading in order to measure the elastic strain during the tensile creep test. Figure 12 shows the creep strain and the specific creep of the normal concrete (N3-30). The creep strains were evaluated by subtracting the non-loading strain and the elastic strain from the loading strain, assuming that the elastic strain was constant at the start of the loading. The specific creep obtained by dividing the creep strain

Table 4 Splitting tensile strength at loading-start age and loading stress

\begin{tabular}{llll}
\hline Test I.D. & s/s ratio $^{\boldsymbol{a}}$ & Splitting tensile strength & Loading stress \\
\hline N3-30a & $30 \%$ & $2.38 \mathrm{MPa}$ & $0.714 \mathrm{MPa}$ \\
N3-30b & $30 \%$ & $1.22 \mathrm{MPa}$ & $0.366 \mathrm{MPa}$ \\
N3-30c & $30 \%$ & $2.09 \mathrm{MPa}$ & $0.627 \mathrm{MPa}$ \\
N3-40a & $40 \%$ & $2.56 \mathrm{MPa}$ & $1.02 \mathrm{MPa}$ \\
N3-40b & $40 \%$ & $2.56 \mathrm{MPa}$ & $1.02 \mathrm{MPa}$ \\
N3-40c & $40 \%$ & $2.55 \mathrm{MPa}$ & $1.02 \mathrm{MPa}$ \\
N7-30 & $30 \%$ & $3.11 \mathrm{MPa}$ & $0.933 \mathrm{MPa}$ \\
FA3-30a & $30 \%$ & $1.51 \mathrm{MPa}$ & $0.453 \mathrm{MPa}$ \\
FA3-30b & $30 \%$ & $1.52 \mathrm{MPa}$ & $0.456 \mathrm{MPa}$ \\
FA3-30c & $30 \%$ & $1.52 \mathrm{MPa}$ & $0.456 \mathrm{MPa}$ \\
FA3-40a & $40 \%$ & $2.04 \mathrm{MPa}$ & $0.816 \mathrm{MPa}$ \\
FA3-40b & $40 \%$ & $2.04 \mathrm{MPa}$ & $0.816 \mathrm{MPa}$ \\
FA3-40C & $40 \%$ & $2.07 \mathrm{MPa}$ & $0.828 \mathrm{MPa}$ \\
FA7-30 & $30 \%$ & $2.74 \mathrm{MPa}$ & $0.822 \mathrm{MPa}$ \\
\hline
\end{tabular}

${ }^{a}:$ Stress/strength ratio 


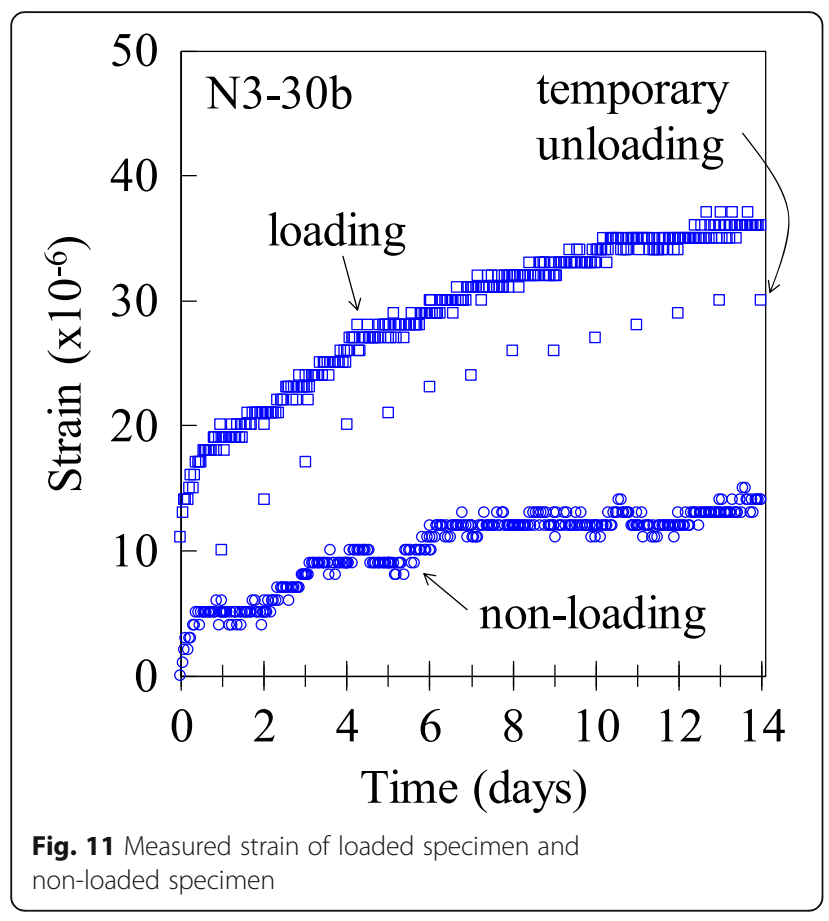

by the loading stress. The loading stresses of N3-30 differed from $0.366 \mathrm{MPa}$ to $0.714 \mathrm{MPa}$ as shown in Fig. 12a), so the creep strain was greater at higher loading stresses. The behaviors of the specific creep shown in Fig. 12b) were relatively similar even at the different loading stresses. In Fig. 12b), the average of the 3 results is also demonstrated. The average specific creep was in the range of $\pm 6 \times 10^{-6} / \mathrm{MPa}$. Figure 13 presents the creep strain and the specific creep of the fly ash concrete (FA3-30) The creep strain behaviors of the fly ash concrete shown in Fig. 13a) were not as clearly different as that of the normal concrete, because the loading stresses for each creep test with fly ash concrete were equivalent. Though the experiment in the present paper cannot indicate a definite factor, the average specific creep of FA3-30 shown in Fig. 13b) had larger errors than that of the normal concrete and was in the range of $\pm 10 \times$ $10^{-6} / \mathrm{MPa}$. It should be noted that the elastic strain at early age decreases as the concrete age increases because of the Young's modulus development during the tensile creep test as shown in Fig. 9.

In this study, two sets of elastic strains for tensile creep behavior were evaluated, one was from the measurement during the tensile creep test, and the other was estimated by dividing the loading stress to the Young' modulus based on the Hooke's Law, as shown in Figs. 14 and 15 . The estimated strains at the start of the loading were not equal to the elastic strains from the measurement, so the modified strain was evaluated by multiplying the ratio $\alpha$ of the measured strain to the estimated strain at the loading. Both the measured strains and the modified strains were decreased with increasing ages. This result indicates that the creep determined from assuming a constant elastic strain has been underestimated. The modified strain of N7-30 was equivalent to the measured strain at the end of loading. However, the modified strains such as N3-30b had a different behavior with the measured strains during the tensile creep test. The elastic strains, shown as red lines in Figs. 14 and 15 , for evaluating the creep in this study were therefore determined with reference to the measured strains rather than the modified strains. It can be seen that the applied strain of N3-30b decreased in 2 days, while the elastic strains of N7-30 decreased more gradually.

Figure 16 shows the specific creep based on the decreasing elastic strains. The dotted lines in Fig. 16

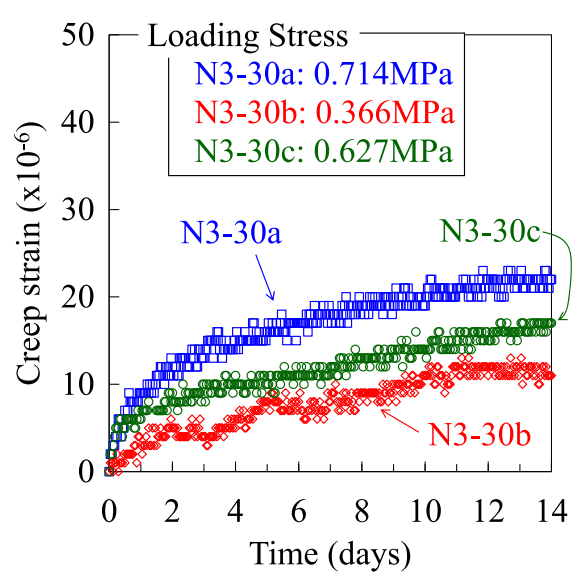

a) Creep strain

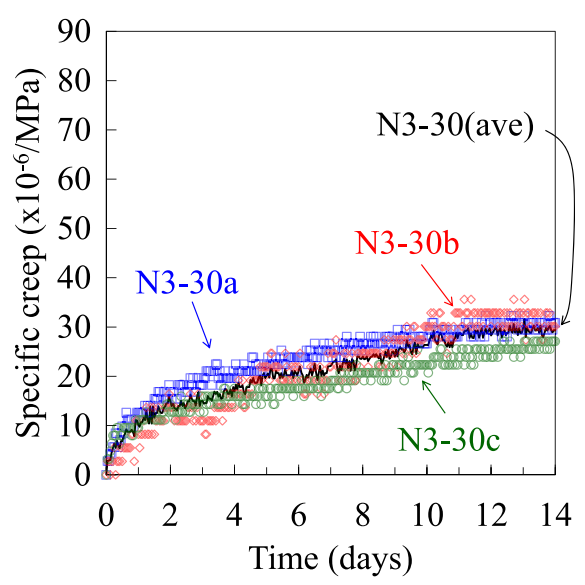

b) Specific creep

Fig. 12 Creep strain and specific creep based on constant elastic strain (N3-30) 


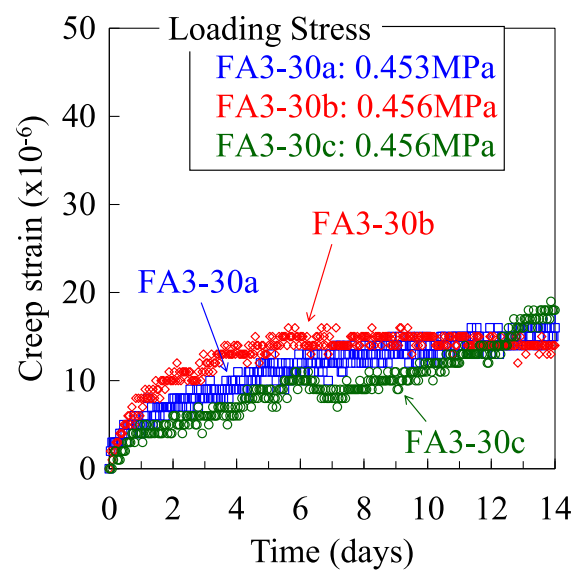

a) Creep strain

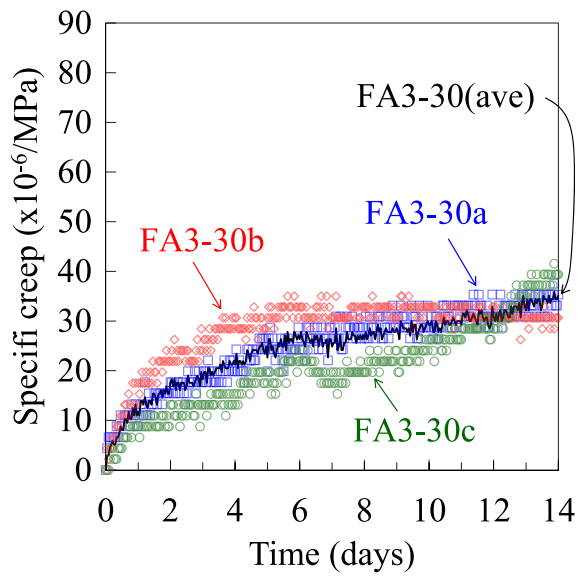

b) Specific creep

Fig. 13 Creep strain and specific creep based on constant elastic strain (FA3-30)

represent the results when using the constant elastic strain. In the case when the load started at the age of 3 days, the difference in the specific creep caused by considering the development of the Young's modulus expanded with decreasing the elastic strain. In this case, the maximum increase of the specific creep of the normal concrete was $10.1 \times 10^{-6} / \mathrm{MPa}$, and was $8.0 \times 10^{-6} /$ $\mathrm{MPa}$ on average. The fly ash concrete also had the specific creep's maximum increase of $11.7 \times 10^{-6} / \mathrm{MPa}$, and $8.4 \times 10^{-6} / \mathrm{MPa}$ on average. Such increase was larger than the difference in the specific creep caused by mixing fly ash into the normal concrete. In other words, the

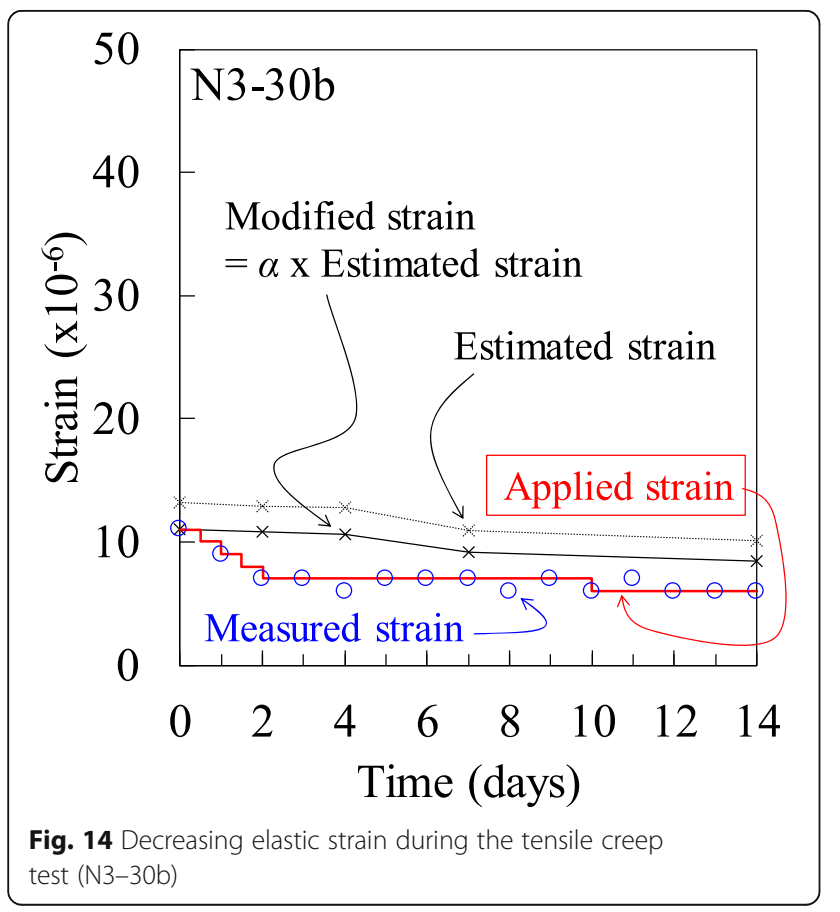

decrease of the elastic strain contributes more in the evaluation of the specific creep than the use of the fly ash mixing. This result indicates that decrease in elastic strain due to stiffness development is more major factor than the effect of fly ash in creep evaluation of fly ash concrete at early age. On the other hands, the specific creep when starting the load at the age of 7 days as shown in Fig. 17 was less affected by the fly ash mixing and the decreasing elastic strain than by starting the load at the age of 3 days.

Figure 18 presents the specific creep of N3-40 with a stress/strength ratio of $40 \%$ at load-starting. One was

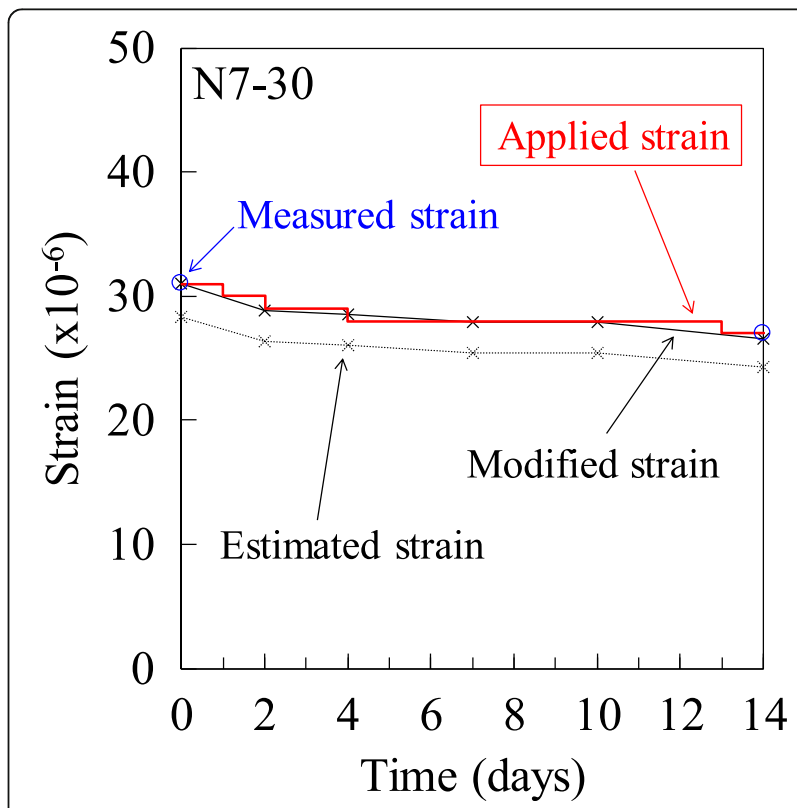

Fig. 15 Decreasing elastic strain during the tensile creep test (N7-30) 


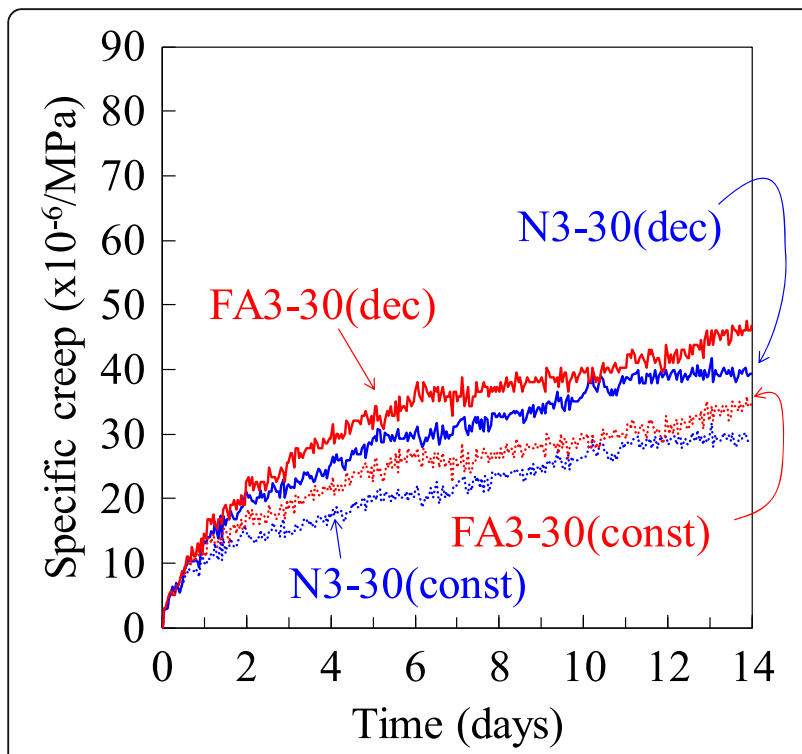

Fig. 16 Specific creep based on the decreasing elastic strain (N3-30 and FA3-30)

relatively similar to $\mathrm{N} 3-30$, and the others were approximately 2-3 times than N3-30. Figure 19 shows the results of FA3-40. The two specific creep behaviors of FA3-40 until 6 days were almost equal to that of FA330 , and the other one was around 1.8 times of FA3-30 at 14 days. The actual stress/strength ratio based on the splitting tensile strength is also shown in Figs. 18 and 19. The stress/strength ratio was decreased from $40 \%$ to less than $30 \%$ in 4 days (age of 7 days). However, the

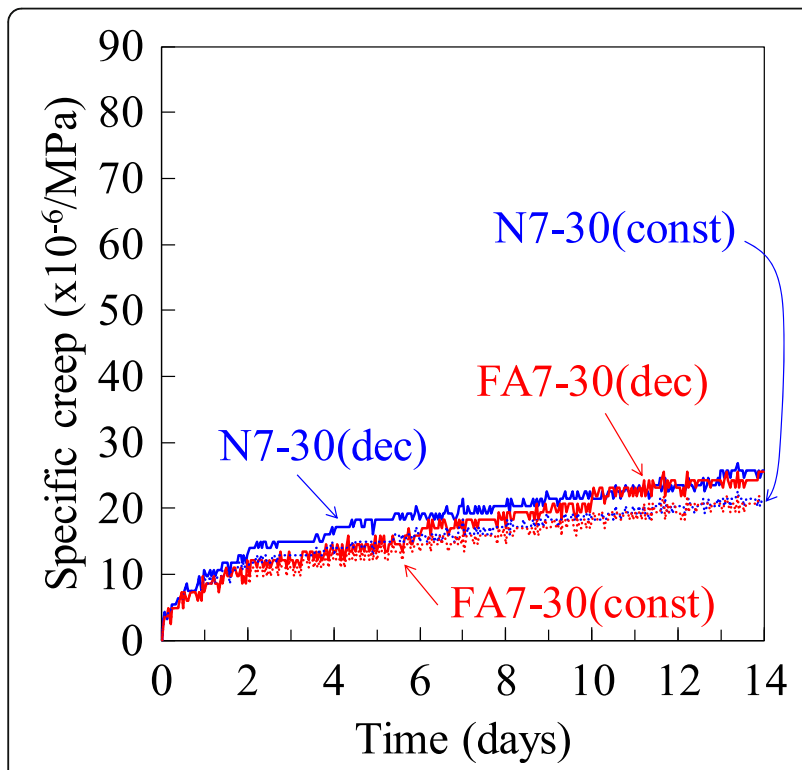

Fig. 17 Specific creep based on the decreasing elastic strain (N7-30 and FA7-30)

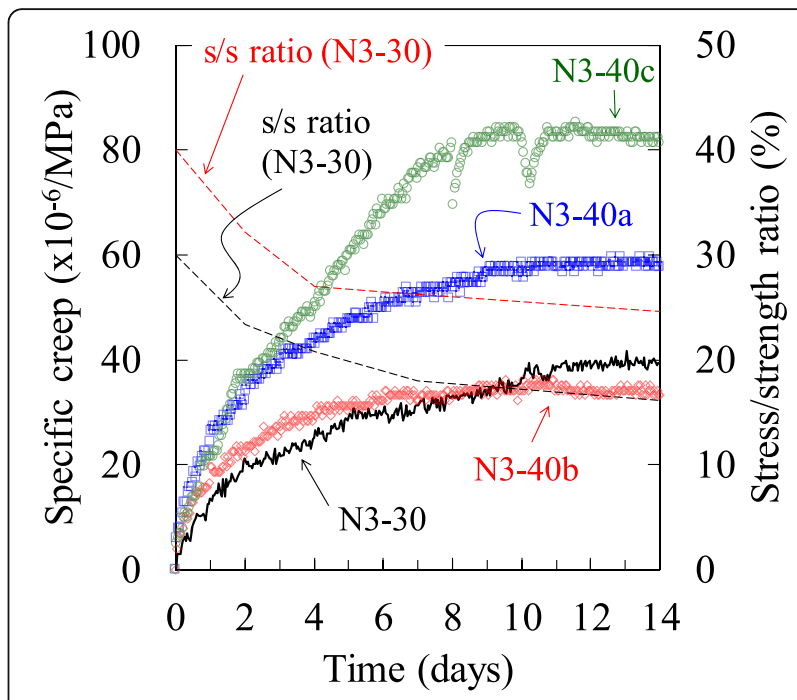

Fig. 18 Specific creep based on the decreasing elastic strain (N3-40)

specific creep behavior of N3-40 and FA3-40 after 4 days differed from that of N3-30 and FA3-30. These results indicate that creep strain with the stress/strain ratio of $40 \%$ might be nonlinear to loading stress and the specific creep of concrete with a stress history which is nonlinear to creep strain might be greater even if a stress/ strength ratio was decreased to less than $30 \%$. In addition, the specific creep of N3-30 and N3-40 at 14 days almost converged, and the specific creep of FA3-30 and FA3-40 was increasing at 14 days yet.

\section{Conclusions}

The present study aimed to obtain the tensile properties for thermal stress analysis of fly ash concrete at early

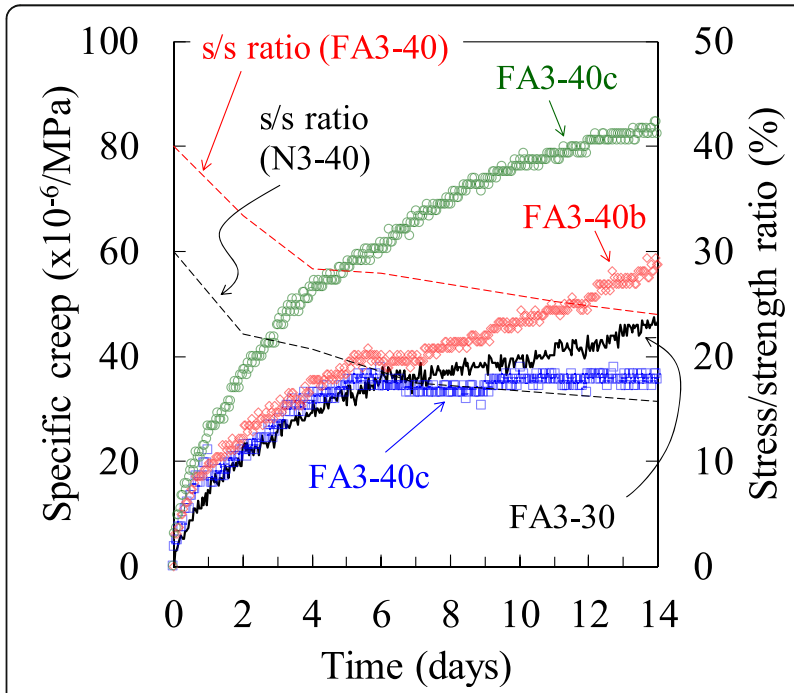

Fig. 19 Specific creep based on the decreasing elastic strain (FA3-40) 
age. This paper describes Young's modulus and tensile creep behavior based on decreasing elastic strain due to development of stiffness. The conclusions of the study are listed as follows:

(1) The secant modulus was found smaller than the tensile Young's modulus, which was $87 \%$ in the present study. The tensile Young's modulus of fly ash concrete at the age of 7 days is almost equal to the linear modulus evaluated with the compressive stress-strain curve at the stress range less than the splitting tensile strength.

(2) The decrease in the elastic strain contributes more to the specific creep when loading started at the age of 3 days than the use of fly ash mixing. The specific creep when loading started at the age of 7 days was less affected by the fly ash mixing and the decreasing elastic strain. The creep strain with stress/strength ratio of $40 \%$ might be nonlinear to loading stress.

\section{Abbreviations}

$\varepsilon:$ Strain; $\sigma:$ Stress; $f_{c}^{\prime}:$ Compressive strength; FEM: Finite Element Method; $f_{t}$ : Splitting tensile strength; HVFA: High volume fly-ash; JIS: Japanese Industrial Standard; $\mathrm{R}^{2}$ : Coefficient of determination; RC: Reinforced concrete; W/cm: Water-cementitious material ratio

\section{Acknowledgements}

The authors would like to acknowledge the Chugoku Electric Power Co. Ltd., for providing fly ash for this research.

\section{Authors' contributions}

YM performed the design of the study and collection, analysis, and interpretation of data, and was a major contributor in writing the manuscript. W contributes to the major revision of the manuscript. IH contributes to the collection of data and supporting the analysis of data. IY contributes to the design of the study and to review the manuscript. All authors read and approved the final manuscript.

\section{Funding}

The authors gratefully acknowledge the financial support of National Institute of Technology, Kure College.

\section{Availability of data and materials}

All data generated or analyzed during this study are included in this published article.

\section{Competing interests}

The authors declare that they have no competing interests.

\begin{abstract}
Author details
'Department of Civil and Environmental Engineering, National Institute of Technology, Kure College, Agaminami 2-2-11, Kure, Hiroshima 737-8506, Japan. ${ }^{2}$ School of Engineering, Macquarie University, 44 Waterloo Rd, Macquarie Park, New South Wales 2113, Australia. ${ }^{3}$ Department of Civil and Environmental Engineering, Yamaguchi University, Tokiwadai 2-16-1, Ube, Yamaguchi 755-8611, Japan.
\end{abstract}

Received: 6 August 2020 Accepted: 14 October 2020

Published online: 23 November 2020

\section{References}

1. Juenger MCG, Siddique R (2015) Recent advances in understanding the role of supplementary cementitious materials in concrete. Cem Concr Res 78:7180. https://doi.org/10.1016/j.cemconres.2015.03.018
2. Moghaddam F, Sirivivatnanon V, Vessalas K (2019) The effect of fly ash fineness on heat of hydration, microstructure, flow and compressive strength of blended cement pastes. Case Stud Constr Mater 10:e00218. https://doi.org/10.1016/j.cscm.2019.e00218

3. Shen D, Shi X, Zhu S, Duan X, Zhang J (2016) Relationship between tensile Young's modulus and strength of fly ash high strength concrete at early age. Constr Build Mater 123:317-326. https://doi.org/10.1016/j.conbuildmat. 2016.06.145

4. Yoshitake I, Komure H, Nassif AY, Fukumoto S (2013) Tensile properties of high volume fly-ash (HVFA) concrete with limestone aggregate. Constr Build Mater 49:101-109. https://doi.org/10.1016/j.conbuildmat.2013.08.020

5. Mimura Y, Yoshitake I, Zhang W (2011) Uniaxial tension test of slender reinforced early age concrete members. Materials 4(8):1345-1359. https://doi.org/10.3390/ma4081345

6. Swaddiwudhiponga S, Lub H-R, Wee T-H (2003) Direct tension test and tensile strain capacity of concrete at early age. Cem Concr Res 33:20772084. https://doi.org/10.1016/S0008-8846(03)00231-X

7. Shen D, Jiang J, Wang W, Shen J, Jiang G (2017) Tensile creep and cracking resistance of concrete with different water-to-cement ratios at early age. Constr Build Mater 146:410-418. https://doi.org/10.1016/j.conbuildmat.2017. 04.056

8. Shen D, Jiang J, Yang J, Shen J, Jiang G (2017) Early-age tensile creep and cracking potential of concrete internally cured with pre-wetted lightweight aggregate. Constr Build Mater 135:420-429. https://doi.org/10.1016/j. conbuildmat.2016.12.187

9. Shen D, Jiang J, Zhang M, Yao P, Jiang G (2018) Tensile creep and cracking potential of high performance concrete internally cured with super absorbent polymers at early age. Constr Build Mater 165:451-461. https://doi.org/10.1016/j.conbuildmat.2016.12.187

10. Bissonnette B, Pigeon M (1995) Tensile creep at early ages of ordinary, silica fume and fiber reinforced concretes. Cem Concr Res 25:10751085. https://doi.org/10.1016/0008-8846(95)00102-1

11. Briffaut M, Benboudjema F, Torrenti J-M, Nahas G (2012) Concrete early age basic creep: experiments and test of rheological modelling approaches. Constr Build Mater 36:373-380. https://doi.org/10.1016/j.conbuildmat.2012. 04.101

12. Japanese Industrial Standard (2015) Fly ash for use in concrete (JIS A 6201) (in Japanese)

13. Japanese Industrial Standard (2018) Method of test for splitting tensile strength of concrete (JIS A 1113) (in Japanese)

14. Japanese Industrial Standard (2017) Method of test for static modulus of elasticity of concrete (JIS A 1113) (in Japanese)

15. Nakamura H, Asakami O, Tanimoto T, Hamada S (1995) Thermal stress analysis of the mass concrete structure based on temperature-dependent properties of concrete. J Mater Concrete Struct Pavements 520:235-247. https://doi.org/10.2208/jscej.1995.520_235 (in Japanese)

\section{Publisher's Note}

Springer Nature remains neutral with regard to jurisdictional claims in published maps and institutional affiliations.

\section{Submit your manuscript to a SpringerOpen ${ }^{\circ}$ journal and benefit from:}

- Convenient online submission

- Rigorous peer review

- Open access: articles freely available online

- High visibility within the field

- Retaining the copyright to your article

Submit your next manuscript at $>$ springeropen.com 